\title{
The Efficacy of Ultrasonic Pest Repellent Devices against the Australian Paralysis Tick, Ixodes holocyclus (Acari: Ixodidae)
}

\author{
Amonrat Panthawong ${ }^{1}$, Stephen L. Doggett ${ }^{2}(\mathbb{B})$ and Theeraphap Chareonviriyaphap ${ }^{1, *}$ \\ 1 Department of Entomology, Faculty of Agriculture, Kasetsart University, Bangkok 10900, Thailand; \\ aor_bio@hotmail.com \\ 2 Department of Medical Entomology, NSW Health Pathology-ICPMR, Westmead Hospital, \\ Westmead, NSW 2145, Australia; Stephen.Doggett@health.nsw.gov.au \\ * Correspondence: faasthc@ku.ac.th; Tel.: +66-81-563-5467
}

\section{check for}

updates

Citation: Panthawong, A.; Doggett, S.L.; Chareonviriyaphap, T. The Efficacy of Ultrasonic Pest Repellent Devices against the Australian Paralysis Tick, Ixodes holocyclus (Acari: Ixodidae). Insects 2021, 12, 400. https://doi.org/10.3390/insects 12050400

Academic Editors: Kirby

C. Stafford III, Scott C. Williams and Megan A. Linske

Received: 7 April 2021

Accepted: 28 April 2021

Published: 30 April 2021

Publisher's Note: MDPI stays neutral with regard to jurisdictional claims in published maps and institutional affiliations.

Copyright: (c) 2021 by the authors. Licensee MDPI, Basel, Switzerland. This article is an open access article distributed under the terms and conditions of the Creative Commons Attribution (CC BY) license (https:// creativecommons.org/licenses/by/ $4.0 /)$.
Simple Summary: Ultrasonic repellers are widely available and marketed to protect against tick bite. To date, there has been no research on the effectiveness of ultrasonic devices against the Australian paralysis tick, Ixodes holocyclus. Thus, this study tested the effectiveness of nine ultrasonic devices with different sound frequencies against female I. holocyclus. Testing found that ultrasonic devices produced less than $19.5 \%$ repellency. The low-level repellency from ultrasonic repellers means that they cannot be recommended for prevention against tick bite.

\begin{abstract}
Ultrasonic pest repellers are often promoted as a means of protecting people and pets from the bites of hematophagous arthropods, such as ticks. However, to date, there has been no published research on the effectiveness of these devices against the Australian paralysis tick, Ixodes holocyclus Neumann. The purpose of this study was to test the effectiveness of nine ultrasonic devices against female I. holocyclus. Two arenas were constructed, one for the test (with the ultrasonic device) and one for the control (no device). Each arena had a test and an escape chamber, connected by a corridor. Twenty ticks were placed in each test chamber. After the ultrasonic device was operated for $1 \mathrm{~h}$, the number of ticks in both chambers was recorded. Ten replicates were conducted for each device. The average number of ticks that moved from the test to the escape chamber was greater in all the test arenas, with three devices being statistically different from the control. However, the highest percent of ticks that escaped was only $19.5 \%$. This amount is insufficient to offer adequate protection against tick bites and this study adds further weight to previous investigations that ultrasonic devices should not be employed in pest management.
\end{abstract}

Keywords: efficacy testing; non-chemical control; tick bite prevention; tick repellent; ultrasonic repellers

\section{Introduction}

Worldwide, ticks are important vectors in the transmission of a range of pathogenic microorganisms, including protozoa, rickettsiae, bacteria and viruses, to their host animals and to humans [1,2]. In Australia, Ixodes holocyclus, commonly known as the Australian paralysis tick, is the most common species that bite humans and is the main species responsible for inducing tick-related morbidity in humans and pets [3,4]. Not only is the species capable of transmitting rickettsia such as Rickettsia australis Philip (etiological agent of Queensland tick typhus) [3], the bite of the tick can cause potentially life-threatening toxicosis, tick paralysis, and induce a range of allergic reactions, such as $\alpha$-Gal syndrome (mammalian meat allergy) [5,6]. With the controversy surrounding the existence (but unproven) presence of Lyme disease in Australia [7,8], much of the contemporary research on I. holocyclus has focused on potential pathogens the tick may carry. Indeed, a range of bacteria [9] and viruses have been identified from I. holocyclus [10,11], although none of the microbes have yet been linked to human disease. 
To prevent these adverse health effects, it is necessary to avoid being bitten by the tick and the main method of bite prevention is through personal protection methods, such as the application of topical repellents applied to clothing and skin [12]. However, up until recently, research into personal protection methodologies against I. holocyclus has been totally neglected with not one single publication prior to 2019 [13]. Fortunately, Sukkanon et al. recently tested a range of topical and spatial repellents and made recommendations on which were the most effective products at repelling I. holocyclus [13]. Even more recently, Panthawong et al. investigated the use of permethrin-impregnated clothing for repelling I. holocyclus [14].

Other methods of preventing I. holocyclus bites have yet to be explored in any scientific manner and one of the most controversial of these is the use of ultrasonic devices. Not only are such devices widely available through online retailers, they are commonly sold in Australian veterinarian clinics for preventing tick bite in dogs (S. Doggett, personal communication). As over 1000 companion animals every year are affected by tick paralysis [15], such devices, if ineffective, could provide the owner with a false sense of security, thereby risking the pets' health when taken into tick-prone areas.

Ultrasonic sound has a frequency of more than $20 \mathrm{kHz}$, which many arthropods can detect [16]. Some arthropods have been reported to be repelled by ultrasonic frequencies in the range of 25 to $65 \mathrm{kHz}$ [17]. It is thought that this frequency creates stress in the nervous system of arthropods, causing them to move away from the source [16]. However, to date, there have been no published reports that have demonstrated that ultrasonic sound effectively repelled any arthropod pest.

Huang et al. found that commercial ultrasound devices failed to repel ants in both laboratory and field trials [18]. A lack of repellency was also reported with cockroaches [19,20], mosquitoes [21], fleas [22,23] and the common bed bug, Cimex lectularius L. [24]. For ticks, there are very few reports that have evaluated the effectiveness of ultrasonic repellents and the one study undertaken to date found such devices ineffective [25]. In spite of the lack of evidence for the efficacy of ultrasonic devices in repelling ticks, as noted above, they are still widely available. In light of their availability and a lack of research on these devices against Australian ticks, the aim of this study was to evaluate the effectiveness of a range of commercially available ultrasonic pest repellent devices to repel I. holocyclus.

\section{Materials and Methods}

\subsection{Ticks}

Adult female I. holocyclus were used in the study as it is this stage that poses the greatest health risk to humans and pets. Ticks were collected by flagging in natural habitats in Irrawong Reserve, New South Wales, Australia $\left(33^{\circ} 41^{\prime} \mathrm{S}, 151^{\circ} 17^{\prime} \mathrm{E}\right)$, over October to November 2019. Collected ticks were maintained in $20 \mathrm{~mL}$ sample jars containing $2 \mathrm{~cm}$ of Plaster of Paris in the base of each jar. The lid of each jar was modified such that a $1 \mathrm{~cm}$ diameter hole was removed and replaced with chiffon fabric that was glued to the lid to allow airflow into the jar. Three drops of distilled water were supplemented into each jar on a regular basis (every few days) to maintain humidity. The ticks were held for $2-4$ days under laboratory conditions at temperatures $25-27{ }^{\circ} \mathrm{C}$ with $70-80 \%$ relative humidity (RH) and 12:12 h (light: dark) prior to testing. As insufficient ticks were collected for the study from the field site, additional, female I. holocyclus were purchased from Australian Veterinary Serum Laboratories, Lismore, NSW. These purchased ticks were collected from undisclosed field sites by individuals on behalf of the company and maintained in the laboratory as above.

\subsection{Ultrasonic Pest Repellent Devices}

Nine commercial ultrasonic pest repellent devices were evaluated (Table 1). They were purchased online through eBay and operated according to manufacturer's instructions. The operating frequency for each device, as provided by manufacturers, is listed in Table 1. Most devices were portable and battery-operated, except for devices $\mathrm{H}$ and $\mathrm{I}$ that required 
AC power and were designed for household use. For the portable ultrasonic devices, devices D and G (according to the manufacturers' claims) were designed for placement around the neck of pets for protection against fleas, ticks, and mosquitoes. Both of these did not list the operating frequency used. From the nine devices, there were five (B, E, F, H, and I) that the instructions claimed that they repelled mosquitoes and other pests, but did not specifically mention ticks. However, these were included in the study to comprehensively test a range of devices that cover different operating frequencies.

Table 1. The nine ultrasonic devices used, along with their frequency (in kilohertz), as stated by the manufacturers.

\begin{tabular}{|c|c|c|}
\hline Devices & Manufacturer & Ultrasonic Frequency (kHz) \\
\hline $\begin{array}{l}\text { A. TICKLESS }{ }^{\circledR} \text { PET Ultrasonic Tick and } \\
\text { Flea Repeller for Pet }\end{array}$ & ProtectONE Ltd., Budapest, Hungary & 40 \\
\hline $\begin{array}{l}\text { B. MOZZIGEAR }{ }^{\mathrm{TM}} \text { Portable Ultrasonic } \\
\text { Mosquito Repeller }\end{array}$ & Intelligent Health Systems, Guangdong, China & $5-20$ \\
\hline $\begin{array}{l}\text { C. TICKLESS }{ }^{\circledR} \text { HORSE Ultrasonic Tick } \\
\text { and Flea Repeller for Horses }\end{array}$ & ProtectONE Ltd., Budapest, Hungary & 40 \\
\hline D. Pet's Pest Repeller & $\begin{array}{l}\text { www.Petshopboyz.com.au, accessed on } \\
28 \text { September 2020, Sydney, Australia }\end{array}$ & $\mathrm{n} / \mathrm{a}$ \\
\hline $\begin{array}{l}\text { E. L1-118 Portable Electronic Insect } \\
\text { Repellent }\end{array}$ & $\begin{array}{l}\text { Shenzhen Dowdon Tech Co., Ltd., } \\
\text { Guangdong, China }\end{array}$ & $9-21$ \\
\hline F. Portable Smart Pest Repeller & $\begin{array}{l}\text { Shenzhen Dowdon Tech Co., Ltd., } \\
\text { Guangdong, China }\end{array}$ & $13-75$ \\
\hline $\begin{array}{l}\text { G. CSB24 Ultrasound device against ticks } \\
\text { and fleas }\end{array}$ & Intelligent Health Systems, Guangdong, China & $\mathrm{n} / \mathrm{a}$ \\
\hline $\begin{array}{l}\text { H. ELECTRONIC HELMINTHES } \\
\text { MACHINE }\end{array}$ & Hunan Goldenserise Tech Co., Ltd., Hunan, China & $22-65$ \\
\hline $\begin{array}{c}\text { I. ULTRASONIC PEST REPELLER } \\
\text { Pest Reject }\end{array}$ & Hunan Goldenserise Tech Co., Ltd., Hunan, China & $50-60$ \\
\hline
\end{tabular}

$\mathrm{n} / \mathrm{a}=$ not provided.

\subsection{Test Chambers}

The testing of the ultrasonic devices was based on the procedures of Huang et al. [18] and Yturralde and Hofstetter [24]. Two test arenas were constructed, one was used as the study group (with an ultrasonic device) and the other as a control (no ultrasonic device). Each test arena comprised of two chambers (each $30 \times 30 \times 30 \mathrm{~cm}^{3}$ ) constructed from transparent Perspex and connected towards the bottom by a cardboard corridor $\left(3 \times 10 \times 10 \mathrm{~cm}^{3}\right)$ that allowed for the ticks to escape (Figure 1). It was possible to close the corridor off with a gate to prevent ticks from entering the escape chamber (' $a$ ' in Figure 1). The ultrasonic devices were tested separately and each was suspended into the 'test' chamber (' $b$ ' in Figure 1) at the height of $20 \mathrm{~cm}$ above the floor of the chamber using a ring stand and $40 \mathrm{~cm}$ away from the escape chamber. Twenty-four hours before the test, the interior of each chamber was lined with Fluon (polytetrafluoroethylene suspension; BioQuip, Rancho Dominguez, CA, USA) along the top $10 \mathrm{~cm}$ to prevent ticks from escaping. After the ultrasonic device was turned on, the lid of each chamber was closed to reduce noise contamination between the chambers. 


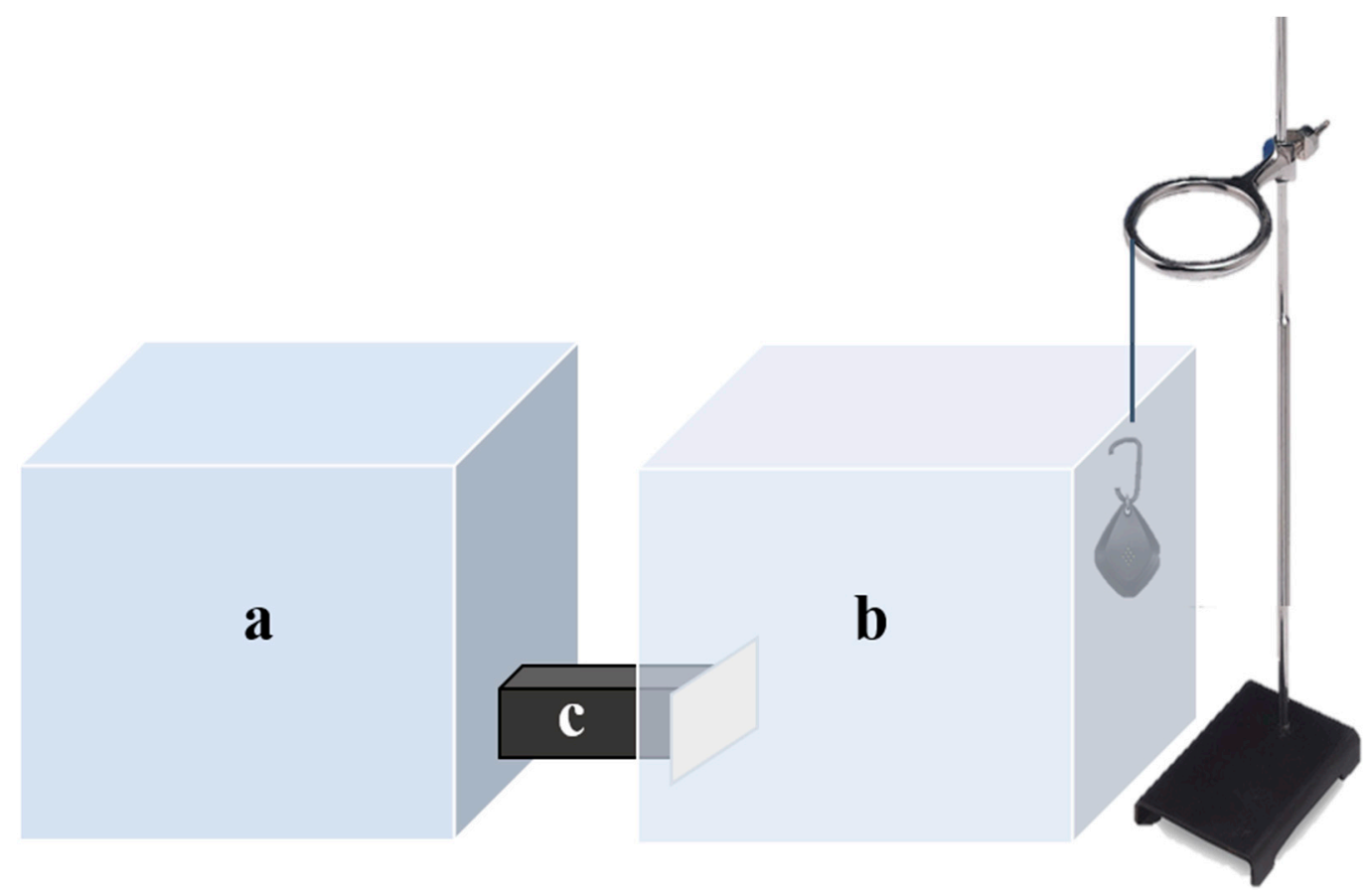

Figure 1. The test chambers used in the trials. The escape chamber (a) connected the test chamber (b) by a cardboard corridor (c). For the treatment, ultrasonic device was suspended at a height of $20 \mathrm{~cm}$ within test chambers by using a ring stand and the other as a control (no ultrasonic device).

\subsection{Testing Procedures}

In each trial, twenty I. holocyclus ticks were introduced into the test chamber and allowed to acclimate to the test conditions for $30 \mathrm{~min}$ with the corridor closed. After the acclimation period, the gate was opened and the ultrasonic device in the test chamber turned on for $60 \mathrm{~min}$. After $60 \mathrm{~min}$, the gate was closed and the number of ticks in each chamber and inside the corridor counted. There were 10 replicates for each device and ten replicates for the controls. Test conditions were $25-27^{\circ} \mathrm{C}$ with $70-80 \%$ RH. Humidity in test chambers was maintained through the trials being conducted in an insectary that has an automatic humidifier controller installed. To reduce any inherent position bias caused by extraneous factors (for example, light from the window), the test arenas were rotated $180^{\circ}$ between each replicate.

\subsection{Data Analysis}

The percentages of ticks that escaped from the ultrasonic devices was calculated by the number of ticks found in both the escape chamber and the corridor multiplied by 100 , and divided by the number of tested ticks (10 replicates: A total of 200 ticks for devices A-H and 60 ticks for device I). The test results were then adjusted from the corresponding controls using Abbott's formula [26]. Data on the number of escaped ticks between the test and control arenas of each device were compared using the Mann-Whitney $U$ test. The null hypothesis ( $\mathrm{H} 0)$ assumes that there were no differences between the tick escape rate in the test and control arenas, while the alternative hypothesis (HA) assumes that they were different. The overall relationship between the number of escaped ticks between the test and control arenas was explored using the Generalized Linear Mixed Models (GLMMs) fitted by the restricted maximum likelihood (REML) approach. The number of escaped ticks was treated as the dependent variable, while trial arenas as the factors, and the devices as the cluster variable. The trial arenas were defined as the fixed effect and device ID as a random effect. Statistical significance for all tests was set at $5 \%(p<0.05)$. Data were analyzed using Jamovi version 1.2 (the Jamovi Project, www.jamovi.org, accessed on 20 January 2020) and SPSS Statistics version 22 (IBM Corp., Armonk, NY, USA). 


\section{Results}

The results of the tests using the nine ultrasonic devices are summarized in Table 2 and graphically depicted in Figure 2. After each ultrasonic device was turned on in the test chamber for $60 \mathrm{~min}$, a number of ticks moved to the escape chamber, with less than $4 \%$ being found in the corridor between the two chambers. However, most of the ticks remained scattered in the test chamber. Similar results were obtained with the control arena. From the trials with the ultrasonic devices, the highest percentage of escaped ticks, when corrected by Abbott's formula from the controls, was with device $\mathrm{D}(19.5 \%, \mathrm{n}=51$, Table 2) followed by F $(16.8 \%, \mathrm{n}=47), \mathrm{I}(12.8 \%, \mathrm{n}=12), \mathrm{B}(11.9 \%, \mathrm{n}=44), \mathrm{G}(11.6 \%, \mathrm{n}=39)$, A $(8.1 \%, n=41), C(7.4 \%, n=38), E(5.5 \%, n=29)$ and $H(4.5 \%, n=31)$. Interestingly, in all the trials, the number of ticks that escaped in the test arena was always greater than the control, albeit not always statistically different (Table 2 and Figure 2). The GLMM analyses revealed that there was a trend of greater repellency in all devices compared to the controls $(p<0.001)$ (Table 3$)$. This repellent effect was only significant for devices B, D, and $\mathrm{F}(p=0.026 ; 0.004 ; 0.014$, respectively). Throughout the whole experiments, no mortality was observed.

Table 2. The number (and percentage) of escaped (chamber a) and non-escaped (chamber b) ticks after one hour of operating the ultrasonic device and the control (no ultrasonic device).

\begin{tabular}{|c|c|c|c|c|}
\hline \multirow{2}{*}{ Devices } & \multirow{2}{*}{ Trials } & \multicolumn{2}{|c|}{ No. of Tick (\%) } & \multirow{2}{*}{$p$-Value } \\
\hline & & Escaped + & Non-Escaped & \\
\hline \multirow[t]{2}{*}{$\mathrm{A}$} & Test & $41(8.1 \ddagger)$ & 159 (79.5) & \\
\hline & Control & $27(13.5)$ & $173(86.5)$ & 0.100 \\
\hline \multirow[t]{2}{*}{ B } & Test & $44(11.9 \ddagger)$ & $156(78)$ & \\
\hline & Control & $23(11.5)$ & 177 (88.5) & $0.026 *$ \\
\hline \multirow[t]{2}{*}{$\mathrm{C}$} & Test & $38(7.4 \ddagger)$ & $162(81)$ & \\
\hline & Control & $25(12.5)$ & 175 (87.5) & 0.071 \\
\hline \multirow[t]{2}{*}{$\mathrm{D}$} & Test & $51(19.5 \ddagger)$ & 149 (74.5) & \\
\hline & Control & $15(7.5)$ & 185 (92.5) & $0.004 *$ \\
\hline \multirow[t]{2}{*}{$\mathrm{E}$} & Test & $29(5.5 \ddagger)$ & $171(85.5)$ & \\
\hline & Control & $19(9.5)$ & $181(90.5)$ & 0.121 \\
\hline \multirow[t]{2}{*}{$\mathrm{F}$} & Test & $47(16.8 \ddagger)$ & $153(76.5)$ & \\
\hline & Control & $16(8)$ & $184(92)$ & 0.014 * \\
\hline \multirow[t]{2}{*}{ G } & Test & $39(10.6 \ddagger)$ & $161(80.5)$ & \\
\hline & Control & $20(10)$ & $180(90)$ & 0.065 \\
\hline \multirow[t]{2}{*}{$\mathrm{H}$} & Test & $31(4.5 \ddagger)$ & $169(84.5)$ & \\
\hline & Control & $23(11.5)$ & 177 (88.5) & 0.055 \\
\hline \multirow[t]{2}{*}{ I } & Test & $12(12.8 \ddagger)$ & $48(80)$ & \\
\hline & Control & $5(8.3)$ & 55 (91.7) & 0.184 \\
\hline
\end{tabular}

* A significant difference $(p<0.05)$ in the number of ticks that escaped between the test and control arenas. + The number and percentage of escaped ticks in both the escape chamber and corridor. $\ddagger$ The percentage of ticks escaped in the tests was corrected from the escaping ticks in the controls using Abbott's formula. 


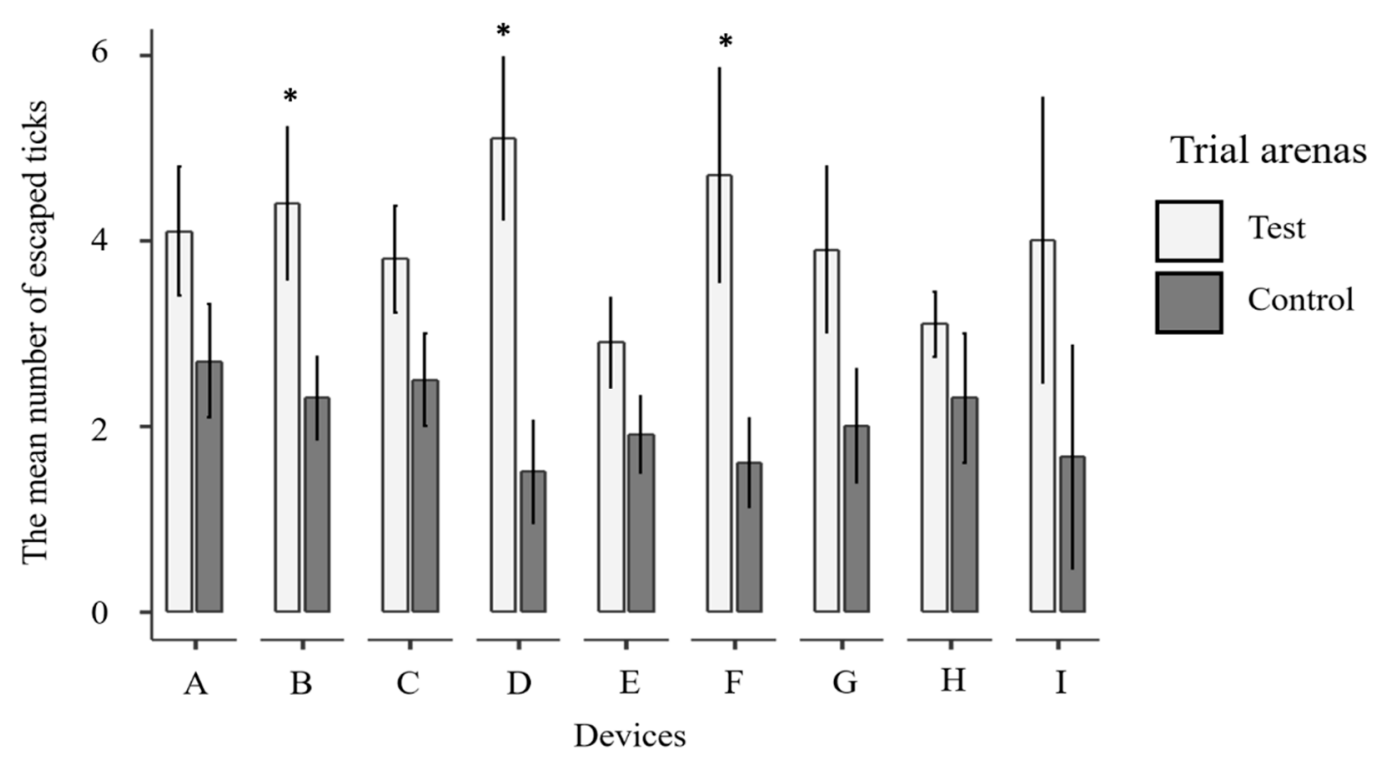

Figure 2. The mean number of ticks escaping (into chamber a) in the ultrasonic treatment and control (no sound) arenas. Error bars represent standard errors. An asterisk ${ }^{*}$ ) above each pair of bars indicates a statistically significant difference.

Table 3. Parameters estimated by the best fit generalized linear mixed model (GLMM).

\begin{tabular}{|c|c|c|c|c|c|c|c|}
\hline \multirow{2}{*}{ Effect } & \multirow{2}{*}{ Estimate } & \multirow{2}{*}{ SE } & \multicolumn{2}{|c|}{ 95\% Confidence Interval } & \multirow{2}{*}{ df } & \multirow{2}{*}{$\mathbf{t}$} & \multirow{2}{*}{$p$-Value } \\
\hline & & & Lower & Upper & & & \\
\hline (Intercept) & 3.04 & 0.162 & 2.73 & 3.36 & 164 & 18.81 & $<0.001$ \\
\hline Control-Test & -1.92 & 0.324 & -2.55 & -1.28 & 164 & -5.92 & $<0.001$ \\
\hline
\end{tabular}

Significance level set at $p<0.05$.

\section{Discussion}

The present study performed the testing of the repellent efficiency of various ultrasonic devices over one hour based on the experimental design of Yturralde and Hofstetter [24]. These researchers turned on the ultrasonic devices immediately for 30 min after 10 bed bugs had been released into the test arenas. For our study, the size of the test arenas $\left(30 \times 30 \times 30 \mathrm{~cm}^{3}\right)$ was comparable to their protocols $(29.85 \mathrm{~cm}$ in diameter, $36.8 \mathrm{~cm}$ in height), although our study employed a greater number of test specimens, namely 20 ticks per trial. Based on the size of our test arenas and number of tested ticks, we adjusted the exposure time to one hour. This amount of time is considered adequate as a device that is claiming to be repellent by the manufacturer should provide complete protection within this time frame.

The overall results of the statistical analyses indicated that some of the tested devices tended to repel ticks compared to the control groups, although the level of repellency observed was very low (less than $20 \%$ ). As more than $80 \%$ of the ticks were not repelled within the confined area, this level of repellency is clearly insufficient to provide adequate protection from a potential tick bite. Our results are comparable to previous reports whereby ultrasonic devices were found unable to repel pests $[18-25,27,28]$. Some studies have focused more on the repellency rate data obtained by statistical analysis rather than the behavior of arthropods after detecting sound waves from an ultrasonic device. In our investigation, ultrasound had some effect on the tick movement. A number of ticks stopped or moved slowly after stimulation of ultrasound-producing devices, which is potentially significant in terms of host protection. In such a scenario, sluggish moving ticks or those that ceased movement were less likely to attach to the host but would after a device was disconnected.

The behavior of ticks in the test arena was observed during trials. After ticks were released in the test chamber and allowed to acclimate for $30 \mathrm{~min}$, they displayed normal 
motility throughout the chamber. Some ticks moved notably slowly after the ultrasonic devices were turned on. The results demonstrated that the frequency of sound did affect tick behavior and movement as a statistically significant repellent effect was recorded in devices B, D, and F, but very low in other devices. Consistent with some previous studies on ultrasonic pest controllers, Yturralde and Hofstetter reported that ultrasonic devices reduced the movement of $C$. lectularius [24]. In contrast, flea behavior was unaffected by ultrasonic devices [28]. Likewise, Brown and Lewis found that ultrasonic devices did not affect the behavior of the tick Rhipicephalus simus, even when the tick was within $1 \mathrm{~cm}$ of the device [25]. These authors also found that ticks under exposure to the ultrasonic frequency still responded to the external stimuli of a gentle exhalation from the experimenter.

As noted in Methods, ultrasonic devices tested were all commercially available and sound frequencies emitted by each as per manufacturers' claims were slightly dissimilar (albeit with considerable overlap). Results showed that all devices poorly repelled I. holocyclus even though there were three significant results. Some devices were not marketed specifically as tick repellents, such as devices B and F. The product manual of device B claimed that it emits very fast and powerful $5-20 \mathrm{kHz}$ multi-frequency sound waves to repel annoying mosquitoes, while device $\mathrm{F}$ is claimed that it can remove mosquitoes and is also effective in repelling pests, such as cockroaches, flies, and even rodents. However, the highest escape percentage of I. holocyclus was only $19.5 \%$ of ticks being repelled. It would be expected that repellency would even be lower in an open field situation, where sound waves would be more dispersed. Several studies have been conducted to test the performance of ultrasonic devices in the field. Ultrasonic pet-collar devices were ineffective in reducing flea numbers on cats $[29,30]$. Additionally, Schein et al. showed no difference between the numbers of fleas and ticks initially placed on dogs with ultrasonic pet-collars and on control dogs, even after 14 days of device operation [29]. For device I in our investigations, which claimed to be capable of repelling a variety of arthropods and animals, only three replicates were performed as the device failed during the experiment.

\section{Conclusions}

In summary, all nine commercial ultrasonic sound pest repellent devices tested in this study demonstrated low-level repellency against I. holocyclus in the confined test arena. However, the small amount of repellency observed would be insufficient to offer adequate protection against tick bites. Thus ultrasonic devices are not recommended for use in the prevention of tick bites from I. holocyclus.

Author Contributions: All authors have contributed significantly to this study. A.P., S.L.D. and T.C. conceived and designed the experiment. A.P. performed the experiment and analyzed the data. A.P. and S.L.D. wrote the manuscript. S.L.D. and T.C. consulted, read, corrected and approved the manuscript. All authors have read and agreed to the published version of the manuscript.

Funding: This research was financially supported by the Thailand Science Research and Innovation (TSRI) through the International Research Network (IRN58W0003) and Kasetsart University Research and Development Institute (Grant\#FF (KU) 14.64).

Institutional Review Board Statement: Not applicable.

Data Availability Statement: All relevant data are included in the article.

Acknowledgments: The authors would like to acknowledge the Tick Induced Allergies Research and Awareness (TIARA) supported the purchase of adult ticks. Our appreciation goes to Merilyn Geary and John Haniotis, Department of Medical Entomology, NSW Health Pathology-ICPMR, Westmead Hospital, assisted in the tick field collections and Ekaphan Kraichak, Department of Botany, Faculty of Science, Kasetsart University, provided advice on the statistical analyses.

Conflicts of Interest: The authors declare no conflict of interest.

\section{References}

1. Jongejan, F.; Uilenberg, G. Ticks and control methods. Rev. Sci. Tech. 1994, 13, 1201-1226. [CrossRef] 
2. Colwell, D.D.; Dantas-Torres, F.; Otranto, D. Vector-borne parasitic zoonoses: Emerging scenarios and new perspectives. Vet. Parasitol. 2011, 182, 14-21. [CrossRef] [PubMed]

3. Doggett, S. Ticks: Human health and tick bite prevention. Med. Today 2004, 5, 33-38.

4. Geary, M.J.; Russell, R.C.; Moerkerken, L.; Hassan, A.; Doggett, S.L. 30 years of samples submitted to an Australian Medical Entomology Department. Austral Entomol. 2021, 60, 172-197. [CrossRef]

5. Rappo, T.B.; Cottee, A.M.; Ratchford, A.; Burns, B.J. Tick bite anaphylaxis: Incidence and management in an Australian emergency department. Emerg. Med. Australas. 2013, 25, 297-301. [CrossRef]

6. Van Nunen, S. Tick-induced allergies: Mammalian meat allergy and tick anaphylaxis. Med. J. Aust. 2018, 208, 316-321. [CrossRef] [PubMed]

7. Collignon, P.J.; Lum, G.D.; Robson, J.M.B. Does Lyme disease exist in Australia? Med. J. Aust. 2016, 205, 1-5. [CrossRef]

8. Chalada, M.J.; Stenos, J.; Bradbury, R.S. Is there a Lyme-like disease in Australia? Summary of the findings to date. One Health 2016, 2, 42-54. [CrossRef]

9. Gofton, A.W.; Doggett, S.L.; Ratchford, A.; Oskam, C.L.; Paparini1, A.; Ryan, U.; Irwin, P. Bacterial profiling reveals novel “Ca. Neoehrlichia", Ehrlichia, and Anaplasma species in Australian human-biting ticks. PLoS ONE 2015, 10, e0145449. [CrossRef]

10. O’Brien, C.A.; Hall-Mendelin, S.; Hobson-Peters, J.; Deliyannis, G.; Allen, A.; Lew-Tabor, A.; Rodriguez-Valle, M.; Barker, D.; Barker, S.C.; Hall, R.A. Discovery of a novel iflavivirus sequence in the eastern [sic] paralysis tick Ixodes holocyclus. Arch. Virol. 2018, 163, 2451-2457. [CrossRef]

11. Harvey, E.; Rose, K.; Eden, J.S.; Lo, N.; Abeyasuriya, T.; Shi, M.; Doggett, S.L.; Holmes, E.C. Extensive diversity of RNA viruses in Australia ticks. J. Virol. 2019, 93, 1-15.

12. Rahlenbeck, S.; Fingerle, V.; Doggett, S.L. Prevention of tick-borne diseases: An overview. Br. J. Gen. Pract. 2016, 66, 492-494. [CrossRef]

13. Sukkanon, C.; Chareonviriyaphap, T.; Doggett, S.L. Topical and spatial repellent bioassays against the Australian paralysis tick, Ixodes holocyclus (Acari: Ixodidae). Austral Entomol. 2019, 58, 866-874. [CrossRef]

14. Panthawong, A.; Chareonviriyaphap, T.; Doggett, S.L. Toxicity and persistence of permethrin-impregnated clothing against the Australian paralysis tick, Ixodes holocyclus (Acari: Ixodidae). Austral Entomol. 2020, 59, 845-851. [CrossRef]

15. Hall-Mendelin, S.; Craig, S.B.; Hall, R.A.; Donoghue, P.O.; Atwell, R.B.; Tulsiani, S.M.; Graham, G.C. Tick paralysis in Australia caused by Ixodes holocyclus Neumann. Ann. Trop. Med. Parasitol. 2011, 105, 95-106. [CrossRef] [PubMed]

16. Tiwari, D.K.; Ansari, M.A. Electronic Pest Repellent: A Review. In Proceedings of the IEEE Sponsored 3rd International Conference on Innovation in Information Embedded and Communication Systems, Tamul Nadu, India, 17-18 March 2016; pp. 435-439.

17. Cheruiyot, E.K. Design and Test of an Electronic Mosquito Repellent; Project Report; School of Science and Engineering and Technology, Kabarak University: Nakuru, Kenya, 2013.

18. Huang, F.; Subramanyam, B.; Clark, J. Laboratory and field trials with commercial ultrasonic devices against three ant species (Hymenoptera: Formicidae). J. Agric. Urban Entomol. 2002, 19, 25-28.

19. Koehler, P.G.; Patterson, R.S.; Webb, J.C. Efficacy of ultrasound for German cockroach (Blattella germanica) (Orthoptera: Blattellidae) and oriental rat flea (Xenopsylla cheopis)(Siphonaptera: Pulicidae) control. J. Econ. Entomol. 1986, 79, 1027-1031. [CrossRef] [PubMed]

20. Huang, F.; Bhadriraju, S. Lack of repellency of three commercial ultrasonic devices to the German cockroach (Blattodea: Blattellidae). Insect Sci. 2006, 13, 61-66. [CrossRef]

21. Sylla, H.K.; Lell, B.; Kremsner, P.G. A blinded, controlled trial of an ultrasound device as mosquito repellent. Wien. Klin. Wochenschr. 2000, 112, 448-450.

22. Hinkle, N.C.; Koehler, P.G.; Patterson, R.S. Egg production, larval development, and adult longevity of cat fleas (Siphonaptera: Pulicidae) exposed to ultrasound. J. Econ. Entomol. 1990, 83, 2306-2309. [CrossRef]

23. Dryden, M.W.; Payne, P.A.; Smith, V. Evaluation of the CatanDog's ${ }^{\circledR}$ tag to prevent flea infestations, inhibit flea reproduction or repel existing flea infestations on cats. Vet. Parasitol. 2000, 92, 303-308. [CrossRef]

24. Yturralde, K.M.; Hofstetter, R.W. Efficacy of commercially available ultrasonic pest repellent devices to affect behavior of bed bugs (Hemiptera: Cimicidae). J. Econ. Entomol. 2012, 105, 2107-2114. [CrossRef] [PubMed]

25. Brown, C.R.; Lewis, B.D. The efficacy of ultrasonic pest controllers for fleas and ticks. J. S. Afr. Vet. Assoc. 1991, 62, 110-113. [CrossRef] [PubMed]

26. Abbott, W.S. A method of computing the effectiveness of an insecticide. J. Econ. Entomol. 1925, 18, 265-267. [CrossRef]

27. Foster, W.A.; Lutes, K.I. Tests of ultrasonic emissions on mosquito attraction to hosts in a flight chamber. J. Am. Mosq. Control Assoc. 1985, 1, 199-202. [PubMed]

28. Rust, M.K.; Parker, R.W. Lack of behavioral responses of the cat flea, Ctenocephalides felis (Siphonaptera: Pulicidae), to a broad spectrum of ultrasound. J. Med. Entomol. 1988, 25, 144-146. [CrossRef]

29. Schein, E.; Gothe, R.; Hauschild, S. Ultrasound units against fleas and ticks in dog and cat -only genial to the world around us? Kleintierpraxis 1988, 33, 147-149.

30. Dryden, M.W.; Long, G.R.; Gaafar, S.M. Effects of ultrasonic flea collars on Ctenocephalides felis on cats. J. Am. Vet. Med. Assoc. 1989, 195, 1717-1718. 